\title{
Ramadan Observance during Pregnancy in Germany: a Challenge for Prenatal Care
}

\section{Ramadan während der Schwangerschaft in Deutschland: eine Herausforderung für die Schwangerschaftsvorsorge}

\section{(c) (1) $\odot$}

Authors

Birgit Leimer ${ }^{1,2 *}$, Fabienne Pradella ${ }^{*}$, Anja Fruth ${ }^{3}$, Annette Queißer $^{3}$, Reyn van Ewijk $^{1}$

Affiliations

1 Johannes Gutenberg University Mainz, Mainz, Germany

2 Goethe University Frankfurt am Main, GSEFM, Frankfurt am Main, Germany

3 University Medical Center of Johannes Gutenberg University Mainz, Mainz, Germany

Key words

Ramadan, fasting, prenatal care, gynecology, epidemiology

Schlüsselwörter

Ramadan, Fasten, Schwangerschaftsvorsorge,

Frauenheilkunde, Epidemiologie

received $\quad 16.1 .2018$

revised 25.4.2018

accepted 4.5.2018

Bibliography

DOI https://doi.org/10.1055/a-0633-1720

Geburtsh Frauenheilk 2018; 78: 684-689 @ Georg Thieme

Verlag KG Stuttgart · New York | ISSN 0016-5751

Correspondence

Fabienne Pradella

Johannes Gutenberg University Mainz

55099 Mainz, Germany

fapradel@uni-mainz.de

$\Theta$

Deutsche Version unter:

https://doi.org/10.1055/a-0633-1720

\section{ABSTRACT}

Introduction Fasting during Ramadan while pregnant has been shown to have long-term negative effects on the offspring's physical and cognitive health. Even though most Muslims do not believe pregnant women are obligated to fast during Ramadan, fasting rates of up to $87 \%$ have been reported for pregnant women. No data exists to date about Ramadan adherence and behavior in Germany.

Methods The Mainz Study of Ramadan and Pregnancy surveyed pregnant Muslims and new Muslim mothers in Mainz between October 2016 and January 2017 and collected information on Ramadan adherence and behavior. We also collected data on personal characteristics and opinions, to identify determinants of fasting using statistical analysis.

Results We found that $43 \%$ of pregnant Muslim women fasted at least one day during Ramadan 2016. Women who fasted were significantly younger and less educated. There was no significant difference in terms of country of origin between those women who fasted and those who did not. Only $49 \%$ of women who fasted and $38 \%$ of women who did not fast discussed their Ramadan behavior with their doctor. Less than $2 \%$ of women reported being proactively approached by their doctor.

Conclusion To ensure that pregnant Muslim women living in Germany can make their fasting decision based on objective information, it is necessary to raise awareness about Ramadan fasting during pregnancy among medical professionals in Germany.

\section{ZUSAMMENFASSUNG}

Einleitung Ramadan während der Schwangerschaft ist mit negativen Folgen für die physische und kognitive Gesundheit der Nachkommen verbunden. Obwohl die meisten Muslime denken, dass Ramadan-Fasten während der Schwangerschaft nicht verpflichtend ist, fastet in vielen Ländern ein erheblicher Teil der schwangeren Muslimas. Für Deutschland liegen bislang keine Daten zum Fasten- und allgemeinen Ramadanverhalten schwangerer Muslimas vor. 
Methodik Im Rahmen der Mainzer Umfragestudie zu Ramadan während der Schwangerschaft wurden zwischen Oktober 2016 und Januar 2017 schwangere und frisch entbundene Muslimas zu ihrem Ramadanverhalten befragt. Auch persönliche Daten und Meinungen der Frauen wurden erhoben, um Bestimmungsfaktoren für die Fastenentscheidung anhand statistischer Analysen identifizieren zu können.

Ergebnisse Es haben $43 \%$ der schwangeren Muslimas in Mainz im Ramadan 2016 gefastet. Fastende Frauen waren signifikant jünger und wiesen einen niedrigeren Bildungsstand auf. Einen Unterschied im Fastenverhalten hinsichtlich der Mi- grationsgeneration gab es nicht. Nur $49 \%$ der fastenden und $38 \%$ der nicht fastenden Frauen besprachen ihr Verhalten im Ramadan mit ihrem medizinischen Fachpersonal. Weniger als $2 \%$ der Frauen gaben an, proaktiv durch ihren Arzt angesprochen worden zu sein.

Fazit Schwangere Muslimas in Deutschland sollten Zugang zu objektiven Informationen erhalten, auf Basis derer sie ihre Fastenentscheidung treffen können. Hierfür ist eine Sensibilisierung des Fachpersonals zu Ramadan in der Schwangerschaft unabdingbar.

\section{Introduction}

Prenatal exposure to Ramadan has been shown to have negative effects on the offspring's physical and cognitive health. Increased risks for symptoms indicative of type 2 diabetes and coronary heart disease [1] as well as lower BMI in adulthood [2] have been reported. Negative effects on cognitive health outcomes such as lower performance in schools [3-5] and negative effects on labor market participation [5] have also been identified. Due to these negative health effects on the offspring, it is important that medical personnel who interact with pregnant Muslim women are sensitized to the customs and behavior during Ramadan. As the number of Muslims in Germany has increased to over $5 \%$ of the total population and is expected to increase further in the future [6], this is becoming an increasing concern for medical professionals in Germany.

The negative health effects of prenatal Ramadan exposure are generally attributed to maternal fasting during pregnancy. Ramadan lasts 29-30 days and requires the abstinence from food and drink during daylight hours. Among pregnant women who adhere to this diurnal fasting, low serum levels of glucose and alanine as well as elevated levels of free fatty acids have been found [7 -9]. Pregnant women skipping meals quickly reach states similar to those of starvation ("accelerated starvation", $[10,11])$. Due to the lack of metabolic fuel and the accompanying changes to hormone levels in the blood, negative health effects are expected in the offspring. This can be placed into a broader literature of fetal programming, which has shown that impaired in utero growth due to malnutrition increases the risk of chronic diseases in adulthood $[12,13]$.

Whether or not pregnant women should fast during Ramadan depends on the interpretation of the Quran, though studies in various countries generally find that a considerable percentage of women fast. Different studies have found that the proportion of pregnant women who fast for at least one day during Ramadan varies from $87 \%$ in southeast Michigan, USA [14] and in Singapore [15], to $54 \%$ in the Netherlands [16] and $43 \%$ in Bradford, UK [17]. As immigrant and Muslim populations differ across European countries, studies on Ramadan fasting practices during pregnancy in some countries do not allow inference to be made about other countries. No data exists to date for Ramadan adherence and behavior in Germany.
To fill this gap, the Mainz Study of Ramadan and Pregnancy was conducted in obstetric wards in Mainz (Germany) to collect data on the fasting behavior of pregnant Muslim women. The study offers insights about which women in Germany decide to fast and why. We also investigated behavioral changes, such as changes in the types of foods women consumed even on those days when they did not fast. Our goal is to contribute to the development of patient information services related to Ramadan fasting during pregnancy for Muslims living in Germany.

\section{Materials and Methods}

\section{Data acquisition}

A survey was conducted among pregnant Muslims and new Muslim mothers in both obstetric wards in Mainz between October 2016 and January 2017. In Germany, almost all women give birth in hospital (98.6\% of live births in $2014,98.8 \%$ of live births in 2015), so our study is representative for almost all births in Mainz [18]. As women in Germany usually stay in hospital for 2-3 days after giving birth [19], the interviews were held on three days per week in order to approach most of the relevant population. All Muslim women were asked to participate, whether or not they fasted during Ramadan. Relevant women were identified by either having indicated "Muslim" as their religion on the clinic's patient registration form or by their name.

In addition to asking women about their fasting decision and the number of days they fasted, the questionnaire included questions on nutritional changes during Ramadan, even on those days on which women did not fast. We also inquired about the reasons why women decided to fast or not to fast. Lastly, personal details were collected, including the country of origin and the amount of time spent in Germany. This last question is of particular interest to identify recent refugees, who might differ from Muslims born or raised in Germany in terms of their religious traditions and beliefs.

Surveys were conducted in the participant's mother tongue as often as possible. For this purpose, two research assistants, who spoke Arabic and Turkish in addition to German, were hired and trained to conduct the interviews. Most interviews were conducted in German (46\%), followed by Arabic (34\%), Turkish (19\%) and English (1\%). Before the interview, all participants were asked to sign an informed consent and after the interview, all data 
were pseudonymized. The study was approved by the Ethics Committee of the Rhineland-Palatinate State Chamber of Medicine (Ethikkommission der Landesärztekammer Rheinland-Pfalz).

\section{Statistical analysis}

Statistical analysis was used to investigate whether there are differences between women who fasted and women who did not fast during Ramadan. T-test and Mann-Whitney test (for ordinal variables such as education) and $x^{2}$-test (for categorical variables such as employment status) were used to identify differences in mean values between groups. The significance level was set at $p<0.05$. Stata 15 was used for all statistical analyses.

\section{Results}

Of the women approached to participate in the study, $71 \%$ participated in the study $(n=116)$. Overall, we were able to approach $51 \%$ of the relevant population and ask them to participate. The main reasons for not being able to approach all of the women were language barriers and if women had already been discharged. Other reasons included the presence of visitors or if women were asleep or not in the room.

\section{Fasting behavior}

Of the interviewed women, $43 \%$ stated that they had fasted for at least one day during their pregnancy. Of these women, the majority (54\%) fasted between 20 and 30 days ( $\vee$ Fig. 1$)$. \ Table 1 shows that there were some differences between the groups of fasting and non-fasting women. Women who fasted during pregnancy were significantly younger, less educated and more likely to wear a veil during the interview.

Women were asked about the reasons (multiple answers were possible) they fasted during Ramadan. Religious reasons and religious obligation were referenced by $64 \%$ of the women. Almost one quarter of the women (24\%) said that they fasted because they wanted to try fasting while pregnant. Women who stopped fasting after a few days explained that they had wanted to fast but were not able to continue because they felt too sick and weak ${ }^{1}$. Women who decided not to fast indicated that they did not fast because of their pregnancy or because they were worried about their baby's health. Five women (4\%) indicated that they did not fast during their pregnancy because they never fast.

\section{Nutrition during Ramadan}

Half of the women who fasted stated that they had adapted their Ramadan eating habits to being pregnant (e.g. "healthier", "regular food intake throughout the night", "drinking more"). On the days they did not fast, $43 \%$ of all women changed their diet because of religious traditions such as breaking their fast at night with sweet food.

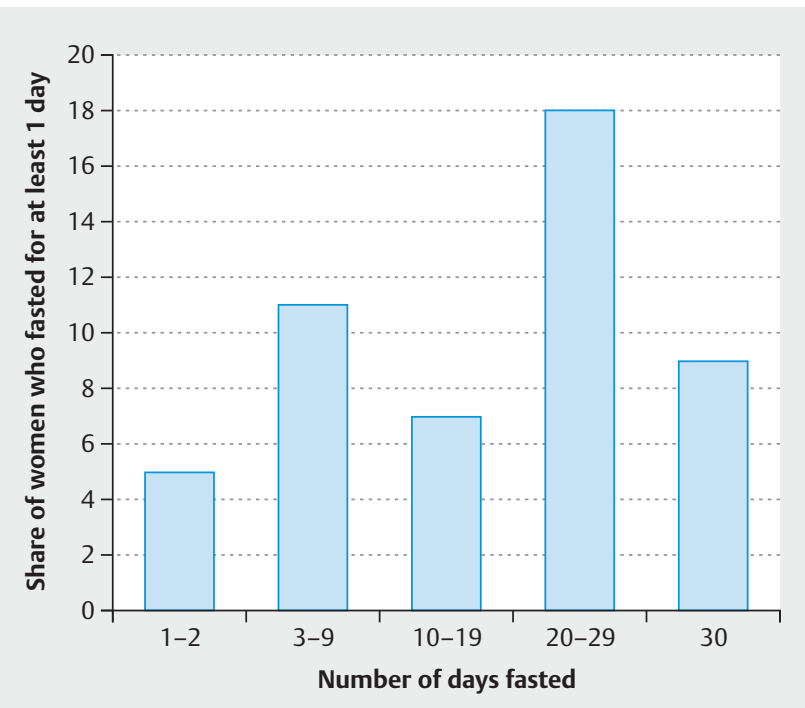

- Fig. 1 Distribution of number of days fasted (among the women who fasted for at least 1 day). The figure shows the percentage of pregnant women who fasted for at least one day during Ramadan $(n=50)$ and how many days they fasted. The classification is based on a personal survey of the pregnant women, who were asked to categorize the number of days they fasted by choosing one of the following options: on a few days (1-2), on some days (3-9), on about half of the days (10-19), on most days (20-29), and on all days (30). Many women reported the exact number of days they fasted, and the classification into categories was then done by the project team.

\section{Living environment}

Fasting women were more likely to live with household members who fasted. Irrespective of the woman's decision about fasting, very few partners of pregnant Muslims believed that pregnant women should fast. Of the women who fasted at least one day during their pregnancy, $6 \%$ of the partners were reported to believe that pregnant women should fast. The partners of the other women either believed that pregnant women should not fast $(48 \%)$, had no opinion (16\%) or thought it was up to the woman to decide, depending on her health $(30 \%)$.

\section{Country of origin}

Most of the participants (77\%) had immigrated to Germany themselves and were thus first-generation immigrants. The majority of first-generation immigrant women were born in Morocco (26\%), Syria $(24 \%)$ or Turkey $(21 \%)$. The parents of women who were born in Germany (23\%, second-generation immigrants) had mainly emigrated from Turkey (ca. 60\%) and Morocco (ca. $20 \%$ ). No participating woman had parents who were both born in Germany. There was no significant difference in terms of country of origin between those women who fasted and those who did not (see $>$ Table 1). 
- Table 1 Characteristics of fasting and non-fasting pregnant Muslims. The table summarizes the characteristics of fasting and non-fasting pregnant women. The investigation into the expected effect of fasting on mother or child asked respondents about the effect fasting had on the health of the child or mother, giving them the option of no effect, positive effect, negative effect. The beliefs of the woman's partner were elicited by asking whether the respondent's partner thought pregnant women should not fast, should fast, or had no opinion.

\begin{tabular}{|c|c|c|c|}
\hline & Did not fast & Fasted & p-value \\
\hline N & 66 & 50 & \\
\hline Age & 31.9 & 29.2 & $0.014^{1)}$ \\
\hline \multicolumn{4}{|l|}{ Education } \\
\hline - did not complete secondary education & $2 \%$ & $7 \%$ & \multirow[t]{4}{*}{$0.007^{2}$} \\
\hline - completed secondary education & $41 \%$ & $65 \%$ & \\
\hline - vocational training & $26 \%$ & $12 \%$ & \\
\hline - university degree & $31 \%$ & $16 \%$ & \\
\hline \multicolumn{4}{|l|}{ Birth country } \\
\hline - born in Germany & $26 \%$ & $20 \%$ & \multirow[t]{3}{*}{$0.375^{3)}$} \\
\hline - lived in Germany < 2 years (not born in Germany) & $24 \%$ & $36 \%$ & \\
\hline - lived in Germany $\geq 2$ years (not born in Germany) & $50 \%$ & $44 \%$ & \\
\hline \multicolumn{4}{|l|}{ Opinions } \\
\hline - fasting has negative effects on child & $67 \%$ & $20 \%$ & $<0.001^{3)}$ \\
\hline - fasting has negative effects on mother & $59 \%$ & $26 \%$ & $<0.001^{3)}$ \\
\hline - my partner thinks pregnant women should fast & $8 \%$ & $6 \%$ & $0.740^{3)}$ \\
\hline \multicolumn{4}{|l|}{ Living environment } \\
\hline - other household members fasted & $80 \%$ & $97 \%$ & $0.019^{3)}$ \\
\hline - advice sought from gynecologist/midwife & $38 \%$ & $49 \%$ & $0.221^{3)}$ \\
\hline - first pregnancy & $42 \%$ & $32 \%$ & $0.252^{3)}$ \\
\hline - veiled/wore a headscarf during the interview & $23 \%$ & $41 \%$ & $0.049^{3)}$ \\
\hline
\end{tabular}

\section{Advice of gynecologists and midwives}

Less than half of the women who fasted (49\%) and even fewer of the women who did not fast (38\%) discussed their behavior during Ramadan with medical professionals. Only two women (2\%) indicated that their doctor had proactively addressed the issue. Of the consulted medical professionals, $73 \%$ had advised the pregnant woman not to fast. Some gynecologists left the decision to the woman (e.g. "if you want to, you can try", "it is up to you, although I would not do it") while others stated that fasting during pregnancy was not risky (e.g. "there are no negative effects as you are in early pregnancy", "if you can manage to fast, it is no problem").

\section{Discussion}

The Mainz Study of Ramadan and Pregnancy is the first study to collect data on the behavior of pregnant Muslims during Ramadan in Germany. We asked 116 pregnant Muslims and new Muslim mothers whether they observed Ramadan and how they behaved during Ramadan while pregnant. Their responses revealed that Ramadan fasting during pregnancy is a relevant topic in Germany, as $43 \%$ of the respondents fasted for at least one day. Due to the various negative long-term health consequences of prenatal ex- posure to fasting for Ramadan, Ramadan fasting during pregnancy should be addressed during prenatal care in Germany.

Our study shows that younger women and women with lower levels of education had a higher tendency to fast in Germany. Consequently, health workers should focus especially on these women when discussing Ramadan behavior during pregnancy. Among the gynecologists and midwives who were asked for advice by our participants, $73 \%$ discouraged the women from fasting; nevertheless, a considerable percentage of women (27\%) reported that they were not made aware of the potential negative effects. The fact that most women did not ask their doctor or midwife for advice both highlights the sensitivity of this religious issue and the importance of health workers proactively addressing Ramadan behavior during pregnancy with their patients.

The challenge for all attempts to offer counseling is that Ramadan fasting during pregnancy is a highly sensitive religious topic. (Perceived) expectations among the religious community may also play a role in a woman's decision whether or not to fast. Otherwise, it is hard to explain why many women who fasted during pregnancy observed Ramadan even though they believed that fasting could harm their child's health ( $20 \%$ of the fasting women) or their own health ( $26 \%$ of the fasting women). In contrast, the partners of the pregnant women in our sample were largely op- 
posed to fasting during pregnancy or left the decision to the woman. Only $6 \%$ of partners of fasting women were reported to believe that pregnant women should fast ( $8 \%$ of the partners of non-fasting women). It is worth noting that $48 \%$ of the fasting women decided to fast, even though their partner indicated that pregnant women should not fast.

The results of the Mainz Study of Ramadan and Pregnancy add to our understanding of the behavior of pregnant Muslim women in Europe. The generalization of the study results to other years and countries should, however, be done with caution, as Ramadan shifts over the years in the Gregorian calendar and the number of daylight hours during which fasting is mandated thus varies. Moreover, immigrant populations differ across European countries. So far, data on Ramadan fasting during pregnancy in Europe are available for the United Kingdom and the Netherlands. In the United Kingdom, 43\% of 310 interviewed pregnant Muslim women of Asian or Asian British ethnicity reported fasting during Ramadan 2010 [17]. In 2010, Ramadan took place from the middle of August to the middle of September, fasting hours were thus shorter than in 2016. Similar to our results, better educated women and older women were less likely to fast. In the Netherlands, Savitri et al. conducted a study on Ramadan 2010 [16]. Of the 130 interviewed women, 54\% fasted at least one day during their pregnancy. In contrast to our results and the study in the United Kingdom, Savitri et al. did not find differences with respect to age or level of education between fasting and non-fasting pregnant Muslims.

It is known that fetal development can be impaired by prenatal malnutrition. Since fasting is a central aspect of Ramadan, previous research has mostly focused on the effects of fasting itself. However, it is possible that other behaviors during Ramadan, in addition to the decision to fast, may negatively affect the offspring. We therefore explored the changes in nutrition during Ramadan, including on those days on which women did not fast. We found that Ramadan also impacted the nutrition of non-fasting pregnant women, as they often lived in households where other members were fasting and participated in religious traditions such as the breaking of the fast after sunset, which is traditionally celebrated with sweet foods and drinks. Consequently, counseling on Ramadan during pregnancy should target both women who fast and women who do not. Moreover, due to a shift in daily routines (e.g., the preparation of breakfast before dawn, dinner after sunset), sleep patterns during Ramadan may also be altered significantly in both fasting and non-fasting individuals [20 - 22]. Previous research has shown that sleep deprivation during pregnancy affects maternal health and fetal birth outcomes $[23,24]$. Therefore, in a follow-up study, we will be exploring the changes in sleep patterns during Ramadan.

The main strength of this study was that we did not rely on registry data but conducted a survey in which we asked the women themselves for detailed information about their religious observance and behavior during Ramadan. For the first time, it was possible to explore the eating behavior of pregnant women during Ramadan beyond the binary decision to fast. It should also be noted that it is very likely that the percentage of fasting pregnant women will vary, depending on when Ramadan occurs in the Gregorian calendar. Lower fasting rates should be expected during the summer months, as occurred in Ramadan 2016 when fasting times were very long and temperatures were high.

Even though the present study is limited by its sample size, we were able to approach a large percentage of affected women in the two obstetric wards in Mainz and had a high response rate. Our results are therefore unlikely to suffer from a large selection bias. However, the survey mainly interviewed women who delivered between October 2016 and January 2017². The overlap between Ramadan 2016 (from the beginning of June until the beginning of July) and pregnancy therefore mainly occurred during the second trimester of pregnancy. In a follow-up study, we intend to explore fasting rates across all trimesters of pregnancy.

\section{Conclusion}

Ramadan fasting during pregnancy is a very relevant topic for Germany, especially in light of the growing Muslim population. Of the interviewed women, $43 \%$ fasted at least 1 day during their pregnancy. The majority of women who decided to fast fasted for more than 20 days. These women decided to fast during pregnancy, even though a large percentage of the women and their partners did not believe it was obligatory to fast. Our findings show that younger and less educated women and pregnant Muslims who wore a headscarf during the interview were more likely to fast. Due to the various long-term negative health effects of in utero exposure to Ramadan fasting and the low percentage of pregnant Muslims who seek advice from medical professionals, gynecologists, midwives and other health workers need to be sensitized and trained to proactively address this sensitive religious topic with their patients. To ensure that women make an informed decision about whether or not to fast, it is important that women receive objective information from health workers about the potential effects of their decision.

\section{Acknowledgements}

This research was funded by DFG (Deutsche Forschungsgemeinschaft), project number 260639091.

\section{Conflict of Interest}

The authors declare that they have no conflict of interest.

2 Our results refer only to inpatient deliveries, as we could not approach Muslim women who opted for a home birth or outpatient delivery. However, inpatient deliveries with hospital stays for 2-3 days are standard in Germany, and very few women choose other options [18]. 


\section{References}

[1] van Ewijk R. Long-term health effects on the next generation of Ramadan fasting during pregnancy. J Health Econ 2011; 30: 1246-1260

[2] van Ewijk RJG, Painter RC, Roseboom TJ. Associations of prenatal exposure to Ramadan with small stature and thinness in adulthood: results from a large Indonesian population-based study. Am J Epidemiol 2013; 177: $729-736$

[3] Almond D, Mazumder B. Health Capital and the Prenatal Environment: The Effect of Ramadan Observance During Pregnancy. Am Econ J Appl Econ 2011; 3: 56-85

[4] Almond D, Mazumder B, van Ewijk R. In utero Ramadan exposure and children's academic performance. The Economic Journal 2015; 125 : 1501-1533. doi:10.1111/ecoj.12168

[5] Majid MF. The Persistent Effects of in Utero Nutrition Shocks Over the Life Cycle: Evidence From Ramadan Fasting. Journal of Development Economics 2015; 117: 48-57

[6] Stichs A. Wie viele Muslime leben in Deutschland? Eine Hochrechnung über die Anzahl der Muslime in Deutschland zum Stand 31. Dezember 2015. Nürnberg: Bundesamt für Migration und Flüchtlinge; 2016

[7] Arab M. Ketonuria and serum glucose of fasting pregnant women at the end of a day in Ramadan. Acta Med Iran 2004; 42: 209-212

[8] Prentice AM, Prentice A, Lamb WH et al. Metabolic consequences of fasting during Ramadan in pregnant and lactating women. Hum Nutr Clin Nutr 1983; 37: 283-284

[9] Malhotra A, Scott PH, Scott J et al. Metabolic changes in Asian Muslim pregnant mothers observing the Ramadan fast in Britain. $\mathrm{Br}$ J Nutr 1989; 61: 663-672

[10] Meis PJ, Rose JC, Swain M. Pregnancy alters diurnal variation of plasma glucose concentration. Chronobiol Int 1984; 1: 145-149

[11] Metzger BE, Vileisis RA, Ravnikar V et al. "Accelerated Starvation" and the Skipped Breakfast in Late Normal Pregnancy. Lancet 1982; 319: 588-592
[12] Keith GM, Barker DJP. Fetal nutrition and adult disease. Am J Clin Nutr 2000; 71: 1344-1352

[13] Barker DJP. The Developmental Origins of Adult Disease: Review. J Am Coll Nutr 2004; 23: 588-595

[14] Robinson T, Raisler J. "Each One is a Doctor for Herself": Ramadan Fasting Among Pregnant Muslim Women in the United States. Ethn Dis 2005; 15: 99-103

[15] Joosoph J, Abu J, Yu SI. A survey of fasting during pregnancy. Singapore Med J 2004; 45: 583-586

[16] Savitri Al, Yadegari N, Bakker J et al. Ramadan fasting and newborn's birth weight in pregnant Muslim women in The Netherlands. Br J Nutr 2014; 112: 1503-1509

[17] Petherick ES, Tuffnell D, Wright J. Experiences and outcomes of materna Ramadan fasting during pregnancy: results from a sub-cohort of the Born in Bradford birth cohort study. BMC Pregnancy Childbirth 2014; 14: 335

[18] Statistisches Landesamt Rheinland-Pfalz. Entbindungen im Krankenhaus 2014-2016. Bad Ems: Statistisches Landesamt Rheinland-Pfalz; 2017

[19] Gesundheitsberichterstattung des Bundes. Diagnosedaten der Krankenhäuser ab 2000. Bonn: Statistisches Bundesamt; 2017

[20] BaHammam AS, Alaseem AM, Alzakri AA et al. The effects of Ramadan fasting on sleep patterns and daytime sleepiness: An objective assessment. J Res Med Sci 2013; 18: 127-131

[21] BaHammam AS. Assessment of sleep patterns, daytime sleepiness, and chronotype during Ramadan in fasting and nonfasting individuals. Saudi Med J 2005; 26: 616-622

[22] Roky R, Chapotot F, Hakkou F et al. Sleep during Ramadan intermittent fasting. I Sleep Res 2001; 10: 319-327

[23] Reutrakul S, Anothaisintawee T, Herring S] et al. Short sleep duration and hyperglycemia in pregnancy: Aggregate and individual patient data meta-analysis. Sleep Med Rev 2018; 40: 31-42

[24] Chang JJ, Pien GW, Duntley SP et al. Sleep deprivation during pregnancy and maternal and fetal outcomes: Is there a relationship? Sleep Med Rev 2010; 14: 107-114 